九州大学学術情報リポジトリ

Kyushu University Institutional Repository

\title{
Thermodynamic Feasibility Evaluation of a Novel Lowtemperature Ejector-based Trans-critical R744 Refrigeration Cycle
}

Mojtaba Purjam

Department of Energy and Environmental Engineering, Interdisciplinary Graduate School of Engineering Sciences, Kyushu University

\section{Kyaw Thu}

Department of Energy and Environmental Engineering, Interdisciplinary Graduate School of Engineering Sciences, Kyushu University

Miyazaki, Takahiko

Department of Energy and Environmental Engineering, Interdisciplinary Graduate School of Engineering Sciences, Kyushu University

https://doi.org/10.5109/4372280

出版情報：Evergreen. 8 (1)，pp.204-212，2021-03. 九州大学グリーンテクノロジー研究教育センター バージョン：

権利関係 : 


\title{
Thermodynamic Feasibility Evaluation of a Novel Low- temperature Ejector-based Trans-critical R744 Refrigeration Cycle
}

\author{
Mojtaba Purjam ${ }^{1, *}$, Kyaw Thu ${ }^{1,2}$, Takahiko Miyazaki ${ }^{1,2}$ \\ ${ }^{1}$ Department of Energy and Environmental Engineering, Interdisciplinary Graduate School of Engineering \\ Sciences, Kyushu University, 6-1 Kasuga-koen, Kasuga-shi, Fukuoka, 816-8580, Japan \\ ${ }^{2}$ Thermal Science and Engineering Division, International Institute of Carbon-Neutral Energy Research \\ (I2CNER), Kyushu University, 744 Motooka, Nishi-ku, Fukuoka 819-0395, Japan \\ *Author to whom correspondence should be addressed: \\ E-mail: purjam.mojtaba.000@s.kyushu-u.ac.jp
}

(Received October 30, 2020; Revised March 25, 2021; accepted March 26, 2021).

\begin{abstract}
In conventional ejector refrigeration cycles, the ejector mostly operates at fixed pressure points in the secondary stream and outlet. Studying the sensitivity of the system to the pressure alternation of the mentioned points has not been investigated. To cover this gap, an extra turboexpander, compressor, and gas cooler were introduced to the conventional ejector layout. It was found that pressurizing the secondary entrance of the ejector could be beneficial to COP if it is not warmer than the gas coolers. Also using the expansion process right after the ejector has the potential to increase the efficiency of the system if the discharge pressure of the ejector reaches supercritical or superheat condition.
\end{abstract}

Keywords: Ejector; Trans-critical $\mathrm{CO}_{2}$; Low-Temperature Refrigeration; Turboexpander

\section{Introduction}

Lorentzen and Petteresen ${ }^{1,2)}$ considered carbon dioxide as an unharmful and environmentally friendly refrigerant that has several positive characteristics such as low toxicity, inexplosive, high capacity to mass ratio, lubricants-compatible, cheap, and unique heat transfer properties. In comparison to conventional heat pump cycles, the compressors of trans-critical $\mathrm{CO}_{2}$ cycles must provide higher lift ${ }^{3}$. Because of this, their COP is usually smaller than other ones with organofluorine-based refrigerants. In order to enhance the COP, researchers tried different layouts and components such as internal heat exchangers ${ }^{4}$, cascade cycles $^{5), 6)}$, turboexpanders ${ }^{7,8)}$, multistage compression ${ }^{9), 10), 11)}$, vortex tube expansions ${ }^{12}$, subcooling boost ${ }^{13), 14)}$.

Along with the described components and methods, the ejectors' implementation approach is favored. $\mathrm{Li}$ and Groll ${ }^{15)}$ and Deng et al. ${ }^{16)}$ suppositionally investigated an ejector in a transcritical $\mathrm{CO}_{2}$ cycle. $\mathrm{Li}$ and Groll ${ }^{15)}$ operated a dual-phase ejector for a transcritical HVAC system and reported a performance gain of up to $16 \%$. It was surfaced that the highest COP in the ejector cycle was $22 \%$ better than other simple vapor compression cycles ${ }^{16)}$. Elbel ${ }^{17)}$ reported that by using an ejector COP and cooling capacity enhanced up to $7 \%$ and $8 \%$ respectively. Banasiak et al. ${ }^{18)}$ conducted a simulation and empirical research over an R744 ejector cycle and announced an $8 \%$ boost in COP compared to a simple throttling valve system. Zhu et al. ${ }^{19)}$ studied a transcritical R744 ejector heat pump-based water heating cycle in the laboratory and proved $10.3 \%$ of increased performance over the single-stage cycle. In a transcritical cycle, gas cooler pressure has a significant effect on COP. There is an optimum pressure that maximizes the COP of the system ${ }^{20,21), 22)}$. Elbel $^{17)}$ reviewed and studied few unconventional layouts for transcritical R744 cycles in a nutshell.

One of the most energy-consuming parts of the refrigeration process in the industries is the lowtemperature refrigeration ${ }^{23)}$. These systems have widespread application, energy-intensive, and usually work non-stop at high capacities. In evaporation temperatures below $-35^{\circ} \mathrm{C}$ the COPs of most refrigeration cycles drop under 1 . Until now there is not a significant specific investigation for using $\mathrm{CO}_{2}$ cycles in this temperature domain. So, proposing and studying new cycles for these temperatures will fill some gaps in transcritical $\mathrm{CO}_{2}$ heat pumping knowledge. From a thermodynamic point of view, if a cycle can present reasonable performance in low temperatures, it has a good chance to be highly efficient in conventional cooling temperatures. Investigation on the reaction of the cycle to 
changing the pressure of 2 inlets and 1 outlet of the ejector is another target of this study.

This paper proposed 3 extra components to the conventional $\mathrm{CO}_{2}$ ejector refrigeration cycle and tried to study the feasibility of the new layout by study the pressure of points before and after the ejector. It is the first step for the parametric analysis.

The coexistence of ejectors and expansion devices in a refrigeration cycle has never been reported. It's mainly since the pressure difference between the flash chamber and evaporator is not significant. However, there is not any mathematical model that proves this. Magnificent pressure lifts in the transcritical R744 cycle and the ejector pressure manipulation gave the research team the chance to investigate the feasibility of simultaneous application of ejector and turboexpanders in this layout.

In the future, full parametric $1^{\text {st }}$ law, $2^{\text {nd }} l_{a w}{ }^{24)}$ and thermo-economics analysis will be done and optimization $^{25)}$ algorithm will be considered in the codes.

\section{The cycle's mathematical model}

\subsection{The schematics and governing equations}

Fig. 1 presents the schematics of the purposed ejector cycle for the deep-freezing cycle.

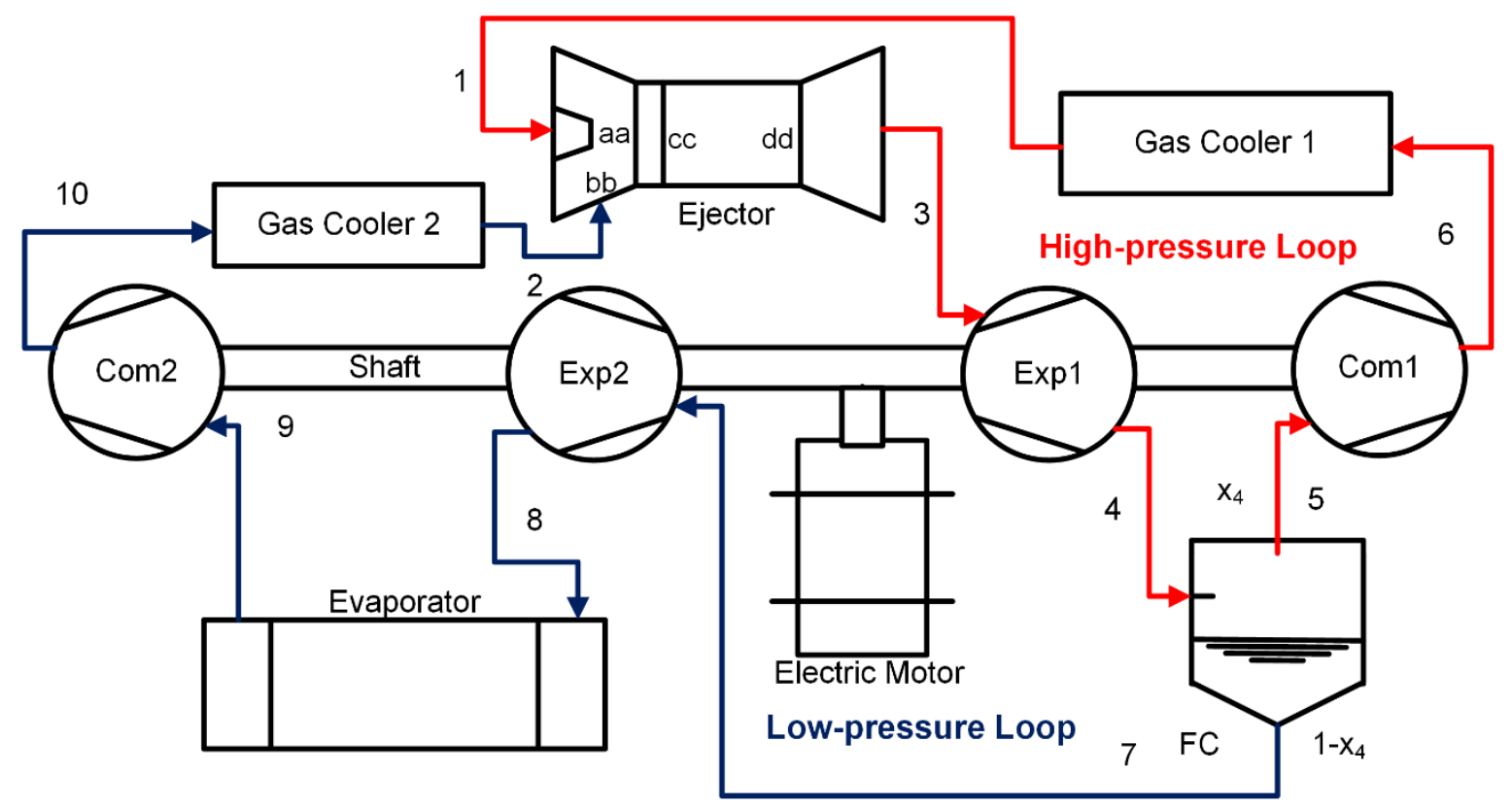

Fig. 1: Schematics of the simulated cycle

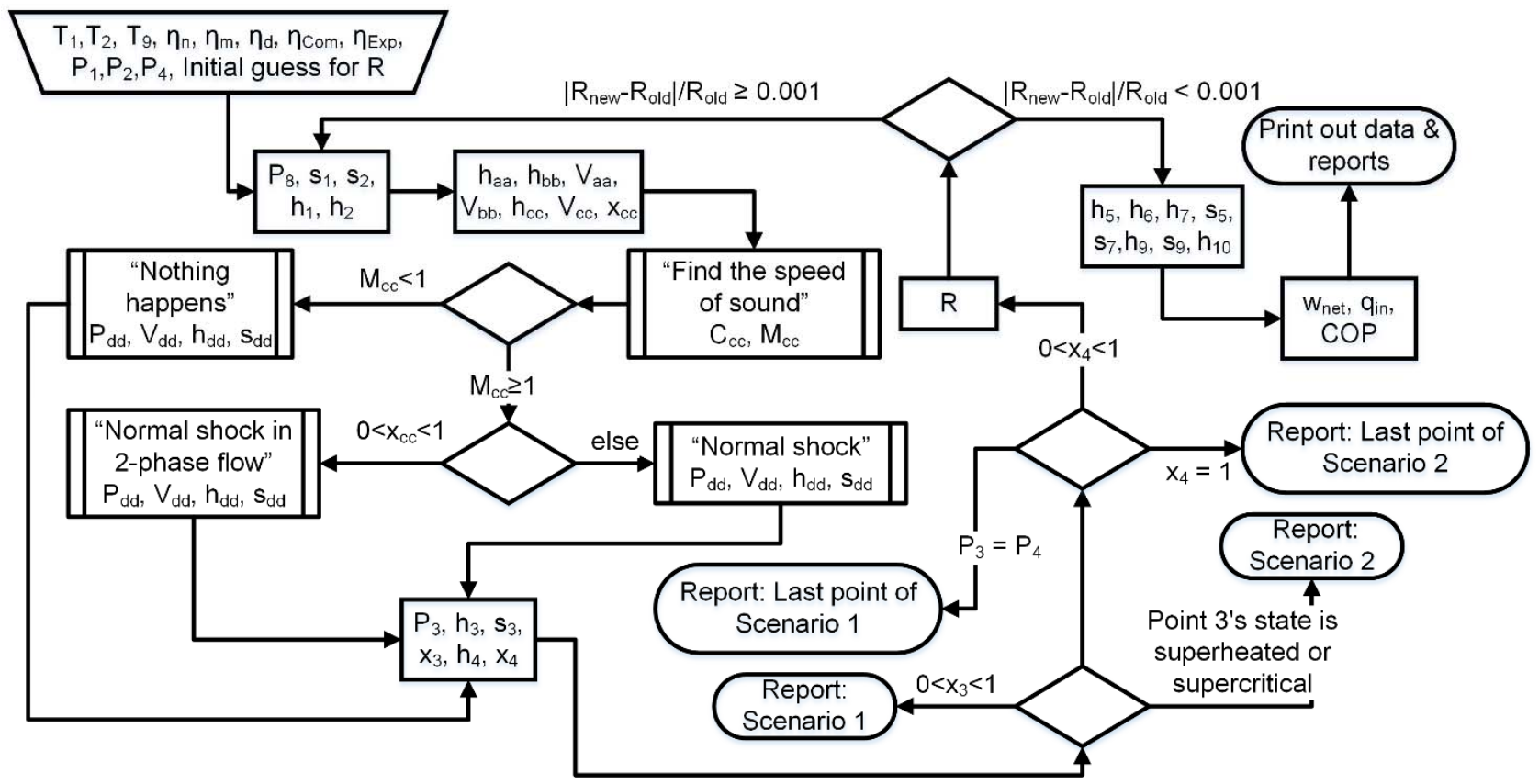

Fig. 2: Program's flowchart in Phyton 


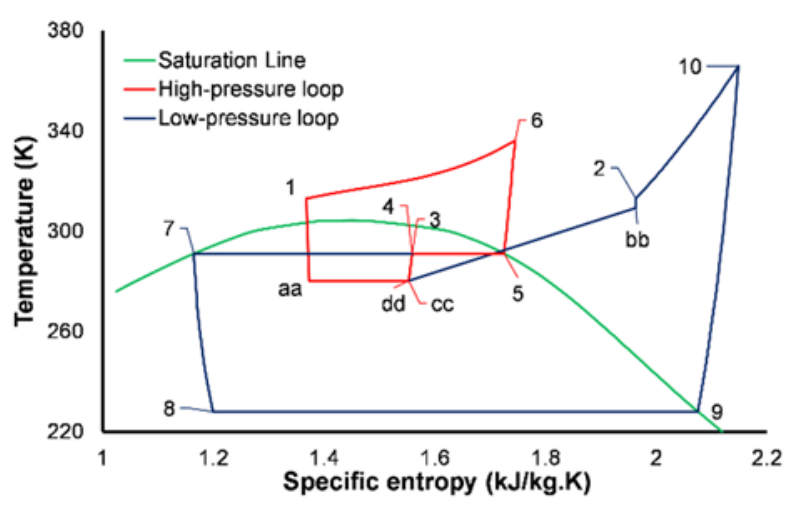

Fig. 3: T-s diagram of the cycle according to Table 1 (1st scenario)

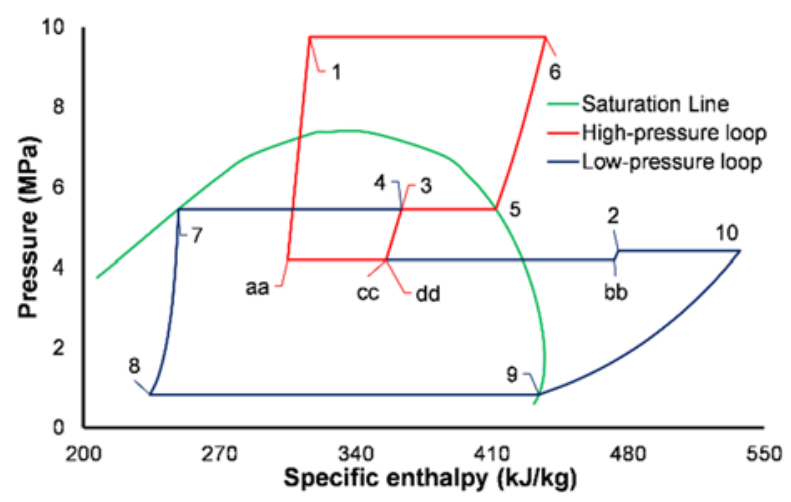

Fig. 4: P-h diagram of the cycle according to Table 1 (1st scenario)

\section{2 $1^{\text {st }}$ law governing equations}

Capacity-independent thermodynamic simulation is the target of this study. Though, the machinery and friction loss is neglected.

Fig. 3 and Fig. 4 show the T-s and P-h diagram of the cycle according to Table 1 .

The first law of thermodynamics for a steady-state steady flow control volume with the negligible potential energy of the flow is:

$$
\begin{aligned}
\dot{Q}-\dot{W} & =\sum \dot{m}_{\text {out }}\left(h_{\text {out }}+\frac{V_{\text {out }}^{2}}{2}\right) \\
& -\sum \dot{m}_{\text {in }}\left(h_{\text {in }}+\frac{V_{\text {in }}^{2}}{2}\right)
\end{aligned}
$$

Mass independent form of the above equation:

$$
\dot{q}-\dot{w}=\sum\left(h_{\text {out }}+\frac{V_{\text {out }}^{2}}{2}\right)-\sum\left(h_{\text {in }}+\frac{V_{\text {in }}^{2}}{2}\right)
$$

The thermophysical properties of R744 were extracted from CoolProp libraries based on non-ideal (non-real gas) conditions ${ }^{26)}$. The simulation environment was mostly Python.

\subsubsection{Compressors and expansion devices}

During compression, the fluid's pressure is increased by compressors. During expansion, the fluid's pressure is reduced by the turboexpanders. Both processes are adiabatic. However, compressors are the work consumers and turboexpanders are the work producers.

The governing equations for compression process:

$$
\begin{gathered}
h_{\text {out }}=h_{\text {in }}+\frac{h\left(P_{\text {out }}, s_{\text {in }}\right)-h_{\text {in }}}{\eta_{\text {Com }}} \\
w_{\text {Com }}=x_{4}\left(h_{6}-h_{1}\right)+\left(1-x_{4}\right)\left(h_{10}-h_{9}\right)
\end{gathered}
$$

The governing equations for the expansion process:

$$
\begin{aligned}
& h_{\text {out }}=h_{\text {in }}-\eta_{\text {Exp }}\left(h_{\text {in }}-h\left(P_{\text {out }}, s_{\text {in }}\right)\right) \\
& w_{\text {Exp }}=h_{3}-h_{4}+\left(1-x_{4}\right)\left(h_{7}-h_{8}\right)
\end{aligned}
$$

\subsubsection{Evaporator}

The specific cooling capacity of the cycle:

$$
q_{E v a}=\left(1-x_{4}\right)\left(h_{9}-h_{8}\right)
$$

The mass flow rate of refrigerant in the evaporator per every refrigeration ton:

$$
\dot{m}_{E v a}=\frac{3516.9}{q_{E v a}}
$$

\subsubsection{Ejector's governing equations}

In the ejector, the primary flow's pressure-drop after the primary nozzle creates a vacuum which in turn sucks in the secondary flow. After that both flows are mixed in the mixing section and finally are discharged out of the ejector by the diffuser. All of the mentioned internal parts of ejector were assumed to be adiabatic except the mixing section which is also isobaric.

\subsubsection{Nozzles' modeling}

Nozzles have an isentropic efficiency. With current assumptions, the nozzles' thermodynamic oriented simulation can be used for the modeling of supersonic and subsonic velocities.

$$
\begin{gathered}
h_{a a}=h_{1}-\eta_{n}\left(h_{1}-h\left(P_{a a}, s_{1}\right)\right) \\
V_{a a}=\left(2\left(h_{1}-h_{a a}\right)\right)^{0.5}
\end{gathered}
$$

The same equations were applied to the secondary nozzle. 
2.2.3.2 Speed of sound in the 2-phase fluid

Niguen et al. ${ }^{27)}$ addressed a mathematical model to calculate the speed of sound in the 2-phase condition.

$$
\begin{aligned}
C^{-1} & =(1-\alpha)\left(\frac{1-\alpha}{C_{l}^{2}}+\frac{\alpha \rho_{l}}{\rho_{v} C_{v}^{2}}\right)^{0.5} \\
& +\alpha\left(\frac{\alpha}{C_{v}^{2}}+\frac{(1-\alpha) \rho_{v}}{\rho_{l} C_{l}^{2}}\right)^{0.5}
\end{aligned}
$$

The $\alpha$ is the void fraction of sub-critical dual-phase fluid.

$$
\alpha=\frac{x \rho_{l}}{x \rho_{l}+(1-x) \rho_{v}}
$$

\subsubsection{Mixing section of ejector}

In the current study, the entrainment ratio of the ejector is decided by the vapor quality before the flash chamber.

$$
R=\frac{\dot{m}_{s}}{\dot{m}_{p}}=\frac{1-x_{4}}{x_{4}}
$$

From the conservation of momentum in an isobaric medium.

$$
V_{a a}+R\left(V_{b b}\right)=(1+R)\left(V_{c c . i d}\right)
$$

Conservation of energy:

$$
\begin{gathered}
h_{a a}+\frac{V_{a a}^{2}}{2}+R\left(h_{b b}+\frac{V_{b b}^{2}}{2}\right) \\
=(1+R)\left(h_{c c, i d}+\frac{V_{c c, i d}^{2}}{2}\right) \\
=(1+R)\left(h_{c c}+\frac{V_{c c}^{2}}{2}\right) \\
\eta_{m}=\frac{V_{c c}^{2}}{V_{c c, i d}^{2}}
\end{gathered}
$$

$V_{c c}$ and $h_{c c}$ are the results in real condition.

2.2.3.4 Normal Shockwave inside the constant area section

If the flow velocity after the mixing section exceeds the speed of the sound, a normal shock will happen in the constant area section. It starts with the conservation of $\operatorname{mass}^{28)}$.

$$
\rho_{c c} V_{c c}=\rho_{d d} V_{d d}
$$

Conservation of momentum:

$$
P_{c c}+\rho_{c c} V_{c c}^{2}=P_{d d}+\rho_{c c} V_{c c} V_{d d}
$$

Conservation of energy:

$$
h_{c c}+\frac{V_{c c}^{2}}{2}=h_{d d}+\frac{V_{d d}^{2}}{2}
$$

Thermodynamic state equation for density:

$$
\rho_{d d}=\rho\left(P_{d d}, h_{d d}\right)
$$

Density's initial guessing value.

$$
\rho_{d d}=\rho_{c c}\left(\frac{(\gamma+1) M_{c c}^{2}}{(\gamma-1) M_{c c}^{2}+2}\right)
$$

In which $\gamma$ for single-phase:

$$
\gamma=\frac{C_{P}\left(P_{c c}, h_{c c}\right)}{C_{V}\left(P_{c c}, h_{c c}\right)}
$$

For dual phase:

$$
\begin{gathered}
\gamma=x_{c c}\left[\frac{C_{P}\left(P_{c c}, x=1\right)}{C_{V}\left(P_{c c}, x=1\right)}\right] \\
+\left(1-x_{c c}\right)\left(\frac{C_{P}\left(P_{c c}, x=0\right)}{C_{V}\left(P_{c c}, x=0\right)}\right)
\end{gathered}
$$

\subsubsection{Diffuser}

$$
\begin{gathered}
h_{3}=h_{d d}+\frac{V_{d d}^{2}}{2} \\
h_{3, i s}=h_{d d}+\eta_{d}\left(h_{3}-h_{d d}\right) \\
P_{3}=P\left(h_{3, i s}, s_{d d}\right) \\
T_{3}=T\left(P_{3}, h_{3}\right)
\end{gathered}
$$

\subsubsection{Coefficient of performance}

$$
\begin{gathered}
C O P=\frac{q_{\text {Eva }}}{w_{\text {Com }}-w_{\text {Exp }}} \\
\text { COP } P_{\text {Carnot }}=\frac{T_{\text {Source }}}{T_{\text {Sink }}-T_{\text {Source }}}
\end{gathered}
$$

The sub-critical 2-phase fluid enters the flash chamber. The saturated vapor is separated from the saturated liquid by the flash chamber in an adiabatic isobaric process. Evaporator and gas coolers are isobaric.

The fixed values in this paper are efficiencies and source and sink temperatures. The efficiencies for nozzles, mixing section, diffuser, compressors, and turboexpanders are $0.9,0.85,0.85,0.75,0.63$ respectively. 
The sink temperature is $303 \mathrm{~K}$ and the source temperature is $233 \mathrm{~K}$. The least temperature difference for gas coolers and the evaporator are 10 and 5 degrees respectively.

Fig. 2 presents the flow chart that calculates the COP of the cycle. The entrainment ratio is the most important part of the simulation and it is must be calculated before calculation of the COP.

\section{Results and discussions}

Table 1 shows the properties of every point in the schematics with some extra information. This is an estimated optimal operation point of this cycle for the fixed source and sink temperatures.

Table 1: The IIR referenced thermo-physical information the points in the schematics in the first scenario

\begin{tabular}{|c|c|c|c|c|c|c|}
\hline State \# & $\mathbf{T}(\mathrm{K})$ & P (MPa) & $\mathrm{h}\left(\mathrm{kJ} \mathrm{kg}^{-1}\right)$ & s $\left(\mathrm{kJ} \mathrm{kg}^{-1} \mathrm{~K}^{-1}\right)$ & Phase or $x(-)$ & Mach Number \\
\hline 1 & 313.0 & 9.750 & 316.3 & 1.368 & Supercritical & 0 \\
\hline aa & 278.4 & 3.990 & 304.2 & 1.373 & 0.4256 & 0.87 \\
\hline 2 & 313.0 & 4.200 & 477.4 & 1.975 & Superheat & 0 \\
\hline $\mathrm{bb}$ & 309.3 & 3.990 & 475.3 & 1.979 & Superheat & 0.27 \\
\hline $\mathrm{cc}$ & 278.4 & 3.990 & 355.8 & 1.558 & 0.6664 & 0.63 \\
\hline $\mathrm{dd}$ & 278.4 & 3.990 & 355.8 & 1.558 & 0.6664 & 0.63 \\
\hline 3 & 290.0 & 5.324 & 364.0 & 1.562 & 0.7042 & 0 \\
\hline 4 & 290.0 & 5.324 & 364.0 & 1.562 & 0.7042 & 0 \\
\hline 5 & 290.0 & 5.324 & 413.7 & 1.734 & 1 & 0 \\
\hline 6 & 337.3 & 9.750 & 440.6 & 1.754 & Supercritical & 0 \\
\hline 7 & 290.0 & 5.324 & 245.8 & 1.155 & 0 & 0 \\
\hline 8 & 228.0 & 0.827 & 232.2 & 1.190 & 0.391 & 0 \\
\hline 9 & 228.0 & 0.827 & 434.1 & 2.075 & 1 & 0 \\
\hline 10 & 361.4 & 4.20 & 534.0 & 2.147 & Superheat & 0 \\
\hline \multicolumn{3}{|c|}{ COP } & 1.342 & \multicolumn{2}{|c|}{ COP $_{\text {Carnot }}$} & 3.329 \\
\hline \multicolumn{3}{|c|}{$\dot{m}_{E v a}$} & $17.4 \mathrm{gr} / \mathrm{s} . \mathrm{TR}$ & \multicolumn{2}{|c|}{$\mathrm{R}$} & 0.42 \\
\hline
\end{tabular}

Table 2: The IIR referenced thermo-physical information the points in the schematics in the second scenario

\begin{tabular}{|c|c|c|c|c|c|c|}
\hline State \# & $\mathbf{T}(\mathbf{K})$ & P (MPa) & h $\left(\mathrm{kJ} \mathrm{kg}^{-1}\right)$ & s $\left(\mathrm{kJ} \mathrm{kg}^{-1} \mathrm{~K}^{-1}\right)$ & Phase or $x(-)$ & Mach Number \\
\hline 1 & 313.0 & 10.50 & 306.1 & 1.332 & Supercritical & 0 \\
\hline aa & 298.3 & 6.460 & 300.3 & 1.334 & 0.2095 & 0.58 \\
\hline 2 & 313.0 & 6.800 & 436.2 & 1.781 & Superheat & 0 \\
\hline $\mathrm{bb}$ & 309.2 & 6.460 & 434.5 & 1.782 & Superheat & 0.27 \\
\hline $\mathrm{cc}$ & 298.3 & 6.460 & 351.3 & 1.505 & 0.6403 & 0.49 \\
\hline dd & 298.3 & 6.460 & 351.3 & 1.505 & 0.6403 & 0.49 \\
\hline 3 & 306.1 & 7.660 & 355.2 & 1.507 & Supercritical & 0 \\
\hline 4 & 289.1 & 5.200 & 350.2 & 1.517 & 0.623 & 0 \\
\hline 5 & 289.1 & 5.200 & 415.2 & 1.742 & 1 & 0 \\
\hline 6 & 344.7 & 10.50 & 447.3 & 1.765 & Supercritical & 0 \\
\hline 7 & 289.1 & 5.200 & 242.7 & 1.145 & 0 & 0 \\
\hline 8 & 228.0 & 0.827 & 229.6 & 1.179 & 0.3833 & 0 \\
\hline 9 & 228.0 & 0.827 & 434.1 & 2.075 & 1 & 0 \\
\hline 10 & 408.5 & 6.80 & 571.0 & 2.162 & Superheat & 0 \\
\hline \multicolumn{3}{|c|}{ COP } & 1.249 & \multicolumn{2}{|c|}{ COP $P_{\text {Carnot }}$} & 3.329 \\
\hline \multicolumn{3}{|c|}{$\dot{m}_{E v a}$} & $17.2 \mathrm{gr} / \mathrm{s} . \mathrm{TR}$ & \multicolumn{2}{|c|}{$\mathrm{R}$} & 0.605 \\
\hline
\end{tabular}


The computed COP illustrates that the current study seems to have a remarkable performance at Table 1 temperatures, even though the assumptions are almost pessimistic. The results look reasonable and they predict no normal shockwaves inside the ejector in these operating conditions. Because of this, future empirical investigations seem to near results.

For the sensitivity analysis, there are supposition and constraints. The pressure after Exp1 cannot be larger than the ejector's outlet pressure. Also, the inlet of the flash chamber must be in the 2-phase state.

Two scenarios for the cycle's operation were assumed. This assumption is based on the behavior of the ejector outlet to the pressure alternation. The first scenario for the time that the purged flow of the ejector is in the 2-phase condition and the second for the time that the purged pressure becomes a single-phase fluid. Depending on the purge pressure, it can be superheated vapor or supercritical fluid. The target of this study is the investigation of the effects of pressure on the COP. The effect of the evaporation and gas cooler temperature is not covered here. In Fig. 2, the point that scenario identified is shown.

The Flash chamber is the separator of the flow of the two loops. If in the sensitivity analysis the inlet flow to the flash chamber turns to single-phase the computation is stopped. These boundaries are shown with the words " 1 st Scenario" or "2nd Scenario" in Fig. 7.

Fig. 5 and Fig. 6 are the P-h and T-s diagrams of the second scenario according to Table 2 .

Fig. 7 shows the COP based on three pressure variable inputs. The same color was chosen for the same purge pressure lines. An important factor in COP is the entrainment ratio which depends on directly the quality of vapor after turboexpander. The optimum maximum pressure of the cycle is between 9 to $11 \mathrm{MPa}$.

The shortest continuous line in Fig. 7 shows the situation without Com 2 and gas cooler. The endpoint of this curve is the situation that there is no first turboexpander in the layout. It can be concluded that this point shows a simple ejector cycle. COP in this point is almost the same as previous studies which is a validation for the calculation of this study. Comparing the COP of the conventional ejector refrigeration cycle with the maximum performance of the current layout, it can be concluded that this novel layout can considerably increase the performance at low-temperature refrigeration.

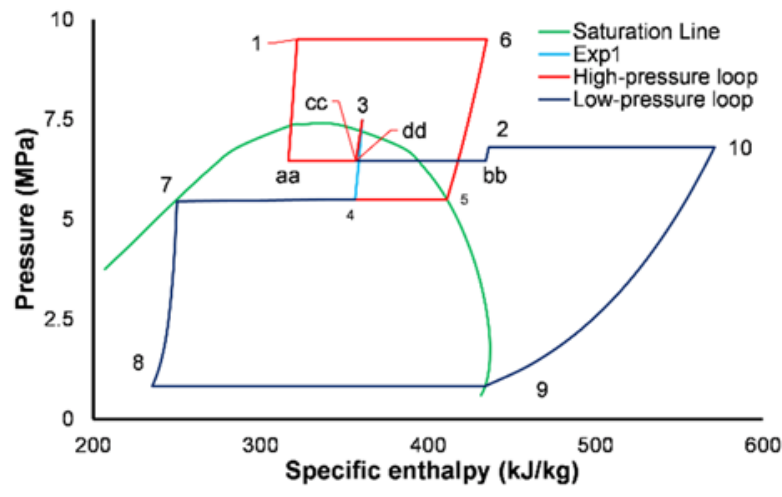

Fig. 5: P-h diagram of the cycle according to Table $2\left(2^{\text {nd }}\right.$ scenario)

Installing compressor after evaporator is beneficial to the performance. It will significantly increase the COP up to an optimal point. However, the necessity of a turboexpander depends on the scenario. If the ejector drives the cycle to the 2 nd scenario, the role of the first turboexpander is vital. It not only increases the COP to a certain amount but also prepares the fluid for the separation in the flash chamber. On the other hand, if the discharge is in 2 phase condition, the first expander becomes unnecessary due to the fact that the optimal operating pressure happens at the end of the curve.

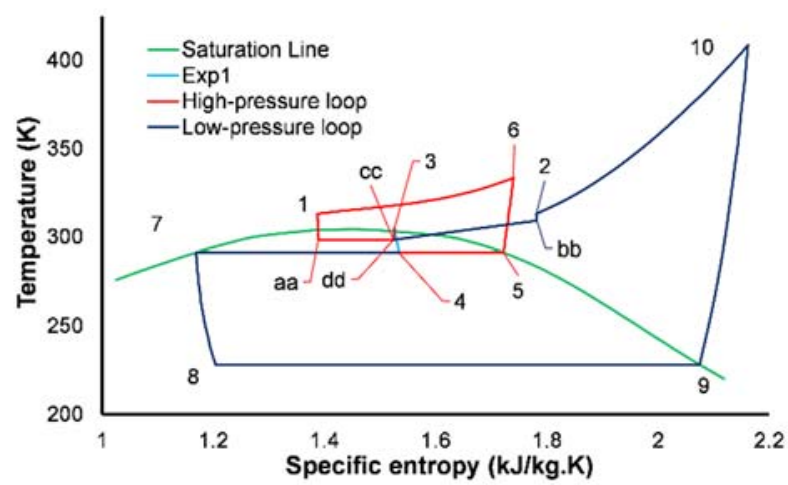

Fig. 6: T-s diagram of the cycle according to Table $2\left(2^{\text {nd }}\right.$ scenario) 


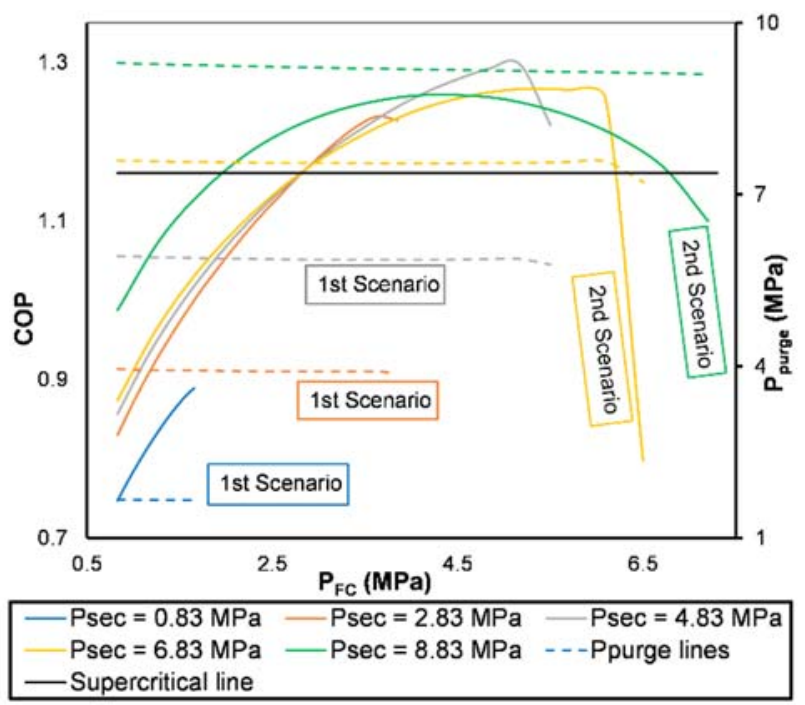

Fig. 7: Pressure-based sensitivity analysis for $\mathrm{P}_{\mathrm{pri}}=10.5 \mathrm{MPa}$

Adding the compressor inevitably increases the pressure of the flash chamber which further boosts the work recovery of Exp2 and the cooling capacity of the evaporator. As it was mentioned in the introduction, simultaneous utilization of the ejector and the turboexpander has not been reported. However, in the current cycle, replacing the throttling valve between the flash chamber and the evaporator with turboexpander seems thermodynamically interesting enough to be economic.

Worthy of mention, the elevation of pressure in the flash chamber leads to shrinkage of the compression ratio in the second compressor which in turn decreases its energy consumption and mechanical problems.

These results are only for one working condition. In the future, several plans must be executed for this research. Full 1st and 2nd law analysis of cycle, thermo-economics and exergoeconomic analysis, improving the cycle performance by making the entrainment ratio more controllable, combining this cycle with other heat pumping and heat engine cycles in parallel and cascade formation and studying the performance of cycle as a heat pump must be performed in the future.

\section{Conclusion}

A novel recommendation for the R744 deep freezing application was presented. In the mathematical model, a simple ejector cycle was modified by adding a compressor and gas cooler between the secondary inlet flow of the ejector the evaporator, and one turboexpander after the ejector's outlet. The coefficient of the performance of the cycle is remarkable (around 1.3 ) at $-45^{\circ} \mathrm{C}$.

After the pressure-based sensitivity analysis of the cycle, it was shown that utilizing these components especially the compressor is beneficial. The turboexpander is unnecessary if the discharge of the ejector is in the 2-phase condition.

\author{
Nomenclature \\ $\mathrm{C}$ : Speed of sound $\left(\mathrm{m} \mathrm{s}^{-1}\right)$ \\ $\mathrm{C}_{\mathrm{P}}$ : Isobaric specific heat capacity $\left(\mathrm{kJ} \mathrm{kg}^{-1} \mathrm{~K}^{-1}\right)$ \\ $\mathrm{C}_{\mathrm{V}}$ : Isochoric specific heat capacity $\left(\mathrm{kJ} \mathrm{kg}^{-1} \mathrm{~K}^{-1}\right)$ \\ COP: Coefficient of performance $(-)$ \\ Com: Compressor \\ Exp: Expansion device or turboexpander \\ Eva: Evaporator \\ FC: Flash chamber \\ $\mathrm{h}$ : Specific enthalpy $\left(\mathrm{kJ} \mathrm{kg}^{-1}\right)$ \\ $\dot{\mathrm{m}}$ : Mass flow rate $\left(\mathrm{g} \mathrm{s}^{-1}\right)$ \\ M: Mach number (-) \\ q: Specific heat energy $\left(\mathrm{kW} \mathrm{kg}^{-1}\right)$ \\ Q: Heat energy $(\mathrm{kW})$ \\ $\mathrm{R}$ : Entrainment ratio \\ $\mathrm{P}$ : pressure $(\mathrm{MPa})$ \\ s: Specific entropy $\left(\mathrm{kJ} \mathrm{kg}^{-1} \mathrm{~K}^{-1}\right)$ \\ $\mathrm{T}$ : Temperature (K) \\ TR: Ton of refrigeration \\ $\mathrm{V}$ : Speed of flow $\left(\mathrm{m} \mathrm{s}^{-1}\right)$ \\ w: Specific Work $\left(\mathrm{kW} \mathrm{kg}^{-1}\right)$ \\ $\mathrm{W}$ : Work $(\mathrm{kW})$ \\ $\mathrm{x}$ : Quality of vapor (-)
}

Greek symbols

$\alpha$ : Void fraction (-)

$\gamma$ : Specific heats ratio (-)

$\rho$ : Density $\left(\mathrm{kg} \mathrm{m}^{-3}\right)$

Subscripts

$1 \sim 10$ : State points number

aa, bb, cc, dd: State points inside the ejector

d: diffuser

id: Ideal

is: Isentropic

in: inlet

1: Liquid

m: Mixing

n: nozzle

out: outlet

pri: primary flow into ejector

purge: purged flow after the ejector

sec: secondary flow into ejector

$\mathrm{v}$ : Vapor

\section{References}

1) G. Lorentzen, "Revival of carbon dioxide as a refrigerant," Int. J. Refrig., 17 (5) 292-301 (1994). doi:10.1016/0140-7007(94)90059-0.

2) J. Lorentzen, Gustav, Pettersen, "A new , efficient and environmentally benign system for car un nouveau syst6me de conditionnement $d$, air automobile efficace et sans nuisance sur 1 , environnement," Int. J.. Refrig., 16 (July) 4-12 (1993).

3) J. Ko, N. Takata, K. Thu, and T. Miyazaki, "Dynamic 
modeling and validation of a carbon dioxide heat pump system," Evergreen, 7 (2) 172-194 (2020). doi: $10.5109 / 4055215$.

4) C. Aprea, and A. Maiorino, "An experimental evaluation of the transcritical co2 refrigerator performances using an internal heat exchanger," Int. $J$. Refrig., $31 \quad$ (6) 1006-1011 (2008). doi:10.1016/j.jirefrig.2007.12.016.

5) S. Bhattacharyya, S. Mukhopadhyay, A. Kumar, R.K. Khurana, and J. Sarkar, "Optimization of a co2-c3h8 cascade system for refrigeration and heating," Int. J. Refrig., $\quad 28 \quad$ (8) 1284-1292 (2005). doi:10.1016/j.jirefrig.2005.08.010.

6) M. Purjam, and K. Goudarzi, "High efficiency subcritical carbon dioxide supplementary heat pump for low temperature climates (energy and exergy analysis)," Renew. Energy, (2019). doi:10.1016/j.renene.2018.10.024.

7) D.M. Robinson, and E.A. Groll, "Efficiencies of transcritical co2 cycles with and without an expansion turbine: rendement de cycles transcritiques au co2 avec et sans turbine d'expansion," Int. J. Refrig., 21 (7) 577-589 (1998). doi:10.1016/S01407007(98)00024-3.

8) J.S. Baek, E.A. Groll, and P.B. Lawless, "Pistoncylinder work producing expansion device in a transcritical carbon dioxide cycle . part i: experimental investigation ' tente et re ' cupe ' ration de travail par piston dans un cycle de ' rimentale transcritique au dioxyde de carbone . partie i :," Int. J. Refrig., $28 \quad 141-151 \quad$ (2005). doi:10.1016/j.ijrefrig.2004.08.006.

9) Y. Hwang, P. D, A. Celik, R. Radermacher, and C. Park, "Performance of co 2 cycles with a two-stage compressor," Refrig. Air Cond., 1-8 (2004).

10) H. Fritschi, F. Tillenkamp, R. Löhrer, and M. Brügger, "Efficiency increase in carbon dioxide refrigeration technology with parallel compression," Int. J. LowCarbon Technol., 12 (2) 171-180 (2017). doi:10.1093/ijlct/ctw002.

11) Z. Zhang, L. Tong, and $X$. Wang, "Thermodynamic analysis of double-stage compression transcritical $\operatorname{co}<\inf >2</$ inf $>$ refrigeration cycles with an expander," Entropy, 17 (4) 2544-2555 (2015). doi:10.3390/e17042544.

12) J. Sarkar, "Cycle parameter optimization of vortex tube expansion transcritical co2 system," Int. J. Therm. Sci., $48 \quad$ (9) 1823-1828 (2009). doi:10.1016/j.ijthermalsci.2009.01.016.

13) R. Llopis, R. Cabello, D. Sánchez, and E. Torrella, "Energy improvements of $\operatorname{co}<$ inf $>2<$ inf $>$ transcritical refrigeration cycles using dedicated mechanical subcooling," Int. J. Refrig., 55 129-141 (2015). doi:10.1016/j.ijrefrig.2015.03.016.

14) J. Sarkar, "Performance optimization of transcritical co 2 refrigeration cycle with thermoelectric subcooler," Int. J. Energy Res., 37 (2) 121-128
(2013). doi:10.1002/er.1879.

15) D. Li, and E.A. Groll, "Transcritical co2 refrigeration cycle with ejector-expansion device," Int. J. Refrig., 28 (5) $766-773$ (2005). doi:10.1016/j.ijrefrig.2004.10.008.

16) J. qiang Deng, P. xue Jiang, T. Lu, and W. Lu, "Particular characteristics of transcritical co 2 refrigeration cycle with an ejector," Appl. Therm. Eng., $\quad 27 \quad(2-3) \quad 381-388 \quad$ (2007). doi:10.1016/j.applthermaleng.2006.07.016.

17) S. Elbel, "Historical and present developments of ejector refrigeration systems with emphasis on transcritical carbon dioxide air-conditioning," Int. J. Refrig., $34 \quad$ (7) 1545-1561 (2011). doi:10.1016/j.jirefrig.2010.11.011.

18) K. Banasiak, A. Hafner, and T. Andresen, "Experimental and numerical investigation of the influence of the two-phase ejector geometry on the performance of the r744 heat pump," Int. J. Refrig., 35 (6) 1617-1625 (2012). doi:10.1016/j.ijrefrig.2012.04.012.

19) Y. Zhu, Y. Huang, C. Li, F. Zhang, and P.X. Jiang, "Experimental investigation on the performance of transcritical co2 ejector-expansion heat pump water heater system," Energy Convers. Manag., 167

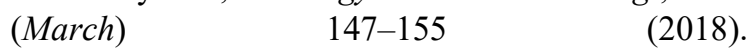
doi:10.1016/j.enconman.2018.04.081.

20) J. Sarkar, "Optimization of ejector-expansion transcritical co2 heat pump cycle," Energy, 33 (9) 1399-1406 doi:10.1016/j.energy.2008.04.007.

21) C. Lucas, and J. Koehler, "Experimental investigation of the cop improvement of a refrigeration cycle by use of an ejector," Int. J. Refrig., 35 (6) 1595-1603 (2012). doi:10.1016/j.ijrefrig.2012.05.010.

22) Y. He, J. Deng, F. Yang, and Z. Zhang, "An optimal multivariable controller for transcritical co2 refrigeration cycle with an adjustable ejector," Energy Convers. Manag., 142 466-476 (2017). doi:10.1016/j.enconman.2017.03.070.

23) M.A. Islam, A. Pal, K. Thu, and B.B. Saha, "Study on performance and environmental impact of supermarket refrigeration system in japan," $\begin{array}{lllll}\text { Evergreen, } & 6 & \text { (2) } 168-176 & \text { (2019). }\end{array}$ doi:10.5109/2321014.

24) M.I. Alhamid, N. Nasruddin, Budihardjo, E. Susanto, T.F. Vickary, and M. Arif Budiyanto, "Refrigeration cycle exergy-based analysis of hydrocarbon (r600a) refrigerant for optimization of household refrigerator," Evergreen, 6 (1) 71-77 (2019). doi:10.5109/2321015.

25) S.A. Shaedi, N. Mohd-Ghazali, J.T. Oh, R. Ahmad, and Y. Mohd-Yunos, "Entropy generation minimization of two-phase flow in a mini channel with genetic algorithm," Evergreen, 6 (1) 39-43 (2019). doi:10.5109/2321004.

26) R. Span, and W. Wagner, "A new equation of state for carbon dioxide covering the fluid region from the 
triple-point temperature to $1100 \mathrm{k}$ at pressures up to 800 mpa," J. Phys. Chem. Ref. Data, 25 (6) 15091596 (1996). doi:10.1063/1.555991.

27) D.L. Nguyen, E.R.F. Winter, and M. Greiner, "Sonic velocity in two-phase systems," Int. J. Multiph. Flow, 7 (3) 311-320 (1981). doi:10.1016/03019322(81)90024-0.

28) T. Oka, T. Handa, F. Akagi, S. Yamaguchi, T. Aoki, K. Yamabe, and Y. Kihara, "Steady-state analysis of supersonic mixing enhanced by a three-dimensional cavity flow," Evergreen, 4 (1) 44-51 (2017). doi:10.5109/1808452. 